\title{
OVINE SYSTEMIC PASTEURELLOSIS CAUSED BY PASTEURELLA HAEMOLYTICA BIOTYPE T
}

\author{
D. A. Dyson, ${ }^{*} \ddagger$ N. J. L. Gilmour $\dagger$ AND K. W. Angus $\dagger$ \\ *East of Scotland College of Agriculture, Veterinary Investigation Centre, Greycrook, \\ St Boswells, Roxburghshire, and $\dagger$ Animal Diseases Research Association, Moredun \\ Research Institute, 408 Gilmerton Road, Edinburgh EH17 $7 \mathrm{JH}$
}

Plate II

\begin{abstract}
SUMmARY. A detailed study was made of lambs aged 5-7 months naturally infected with Pasteurella haemolytica biotype T. In addition to the well known features of such infections, previously unreported necrotic lesions of the tonsil, oesophagus, pharynx and adjacent areas were consistently seen. Large numbers of $P$. haemolytica were present in the tonsil, oesophageal lesions, lung, liver and spleen, but few or none in other tissues. The evidence indicated that the disease was not a true septicaemia. It is postulated that $P$. haemolytica biotype $\mathrm{T}$ already present in the tonsils multiplies and invades the adjacent tissues of the upper alimentary tract; groups of organisms from this site enter the blood stream as emboli, most of which lodge in the capillary beds of the lung and liver; rapid multiplication of organisms in these tissues leads to death from the effects of endotoxin.
\end{abstract}

\section{INTRODUCTION}

Sheep diseases due to Pasteurella haemolytica, biotype A or T, may take one of several forms (Stamp, Watt and Thomlinson, 1955; Smith, 1960a 1961; Gilmour, 1978). Pneumonia, caused by biotype A, affects sheep of all ages. So-called septicaemia consists of two distinct types. One occurs in lambs less than 3 months old; severe pleurisy and pericarditis are present and $P$. haemolytica, usually biotype $A$, can be isolated from all major organs. The other type occurs in lambs aged 5-12 months; it is acute or hyperacute and is almost always caused by biotype-T strains.

The latter disease, first described as septicaemic pasteurellosis by Stamp et al. (1955), was subsequently investigated by Biberstein and Kennedy (1959) and Smith (1960b). Gilmour, Thompson and Fraser (1974) isolated P. haemolytica from the tonsils of $95 \%$ of healthy adult sheep; $65 \%$ of the isolates belonged to biotype $T$. Little further work on the disease has been done,

Received 2 May 1980; revised version accepted 17 Jun. 1980.

$\ddagger$ Present address P.D.U., Juba, Sudan, but requests for reprints should be sent to Dr D. A. Dyson, East of Scotland College of Agriculture, Veterinary Investigation Centre, Greycrook, St Boswells, Roxburghshire. 
although in some areas it constitutes the most important single cause of death in lambs aged 5-12 months (Dyson, unpublished observation). In this paper we present observations on the pathology and bacteriology of the disease, that may help to elucidate its pathogenesis. The observations include a description of hitherto unreported lesions in the throat.

\section{MATERIALS AND MethodS}

Post-mortem examinations. The lambs were submitted for routine diagnosis to St Boswells Veterinary Investigation Centre. They represented typical untreated cases of systemic pasteurellosis and were derived from 15 different outbreaks. Seventeen lambs aged 5-7 months were examined; four were killed when moribund, and the remainder had died not more than a few hours previously. All were examined for macroscopic and microscopic pathological changes, and subjected to routine bacteriological examination; 10 lambs, including three killed when moribund, were subjected to detailed bacteriological studies.

Histopathology. The brain, pieces of lung, liver, spleen, kidney, oesophagus, tonsil, small intestine, abomasum, colon and-when macroscopic lesions were visible-rumen, omasum, tongue and nasal septum, were transported in $10 \%$ Baker's calcium formol; fixation was completed in a modified Bouin's solution (Coop, Angus and Sykes, 1979). Paraffin sections $5 \mu \mathrm{m}$ thick were stained by Mayer's haematoxylin and eosin and by Gram's method.

Quantitative bacteriological examination. The solid medium used for viable counts consisted of Blood Agar Base No. 2 (Oxoid) containing sheep blood $7 \%$, neomycin $5 \mu \mathrm{g} / \mathrm{ml}$, novobiocin 2 $\mu \mathrm{g} / \mathrm{ml}$, and actidione $100 \mu \mathrm{g} / \mathrm{ml}$. This medium inhibited the growth of most organisms present in contaminated material such as oesophageal samples but did not significantly affect $P$. haemolytica.

Samples of lung, liver, spleen, kidney, cerebrum, tonsil, lymph nodes (anterior and posterior mesenteric, and mediastinal), diseased oesophagus and abomasum, and abomasal and ileal contents were stored in individual containers at $-20^{\circ} \mathrm{C}$ for $1-7$ days. Suspensions of tissue $(50 \%, w / v)$ in Nutrient Broth (Oxoid) were prepared by homogenising the still-frozen material for $2 \mathrm{~min}$ in a tissue blender (Colworth Stomacher; A. J. Seward, Bury St Edmunds). Neither the freezing nor the homogenisation significantly affected the viable counts.

Viable counts were made by a modification of the method of Miles, Misra and Irwin (1938). Serial tenfold dilutions of each tissue suspension, and of each sample of abomasal or ileal contents, were made; $0.02-\mathrm{ml}$ volumes of appropriate dilutions were dropped on to blood-agar plates. After overnight incubation at $37^{\circ} \mathrm{C}$ the colonies were counted and the number of viable organisms per gram of original material was calculated. Viable counts were also made of organisms in heparinised blood from two live but moribund lambs; several $0.01-\mathrm{ml}$ volumes of a 1 in 10 dilution were spread over the surface of blood-agar plates and incubated.

Serotyping and biotyping of $P$. haemolytica. Up to three colonies from each tissue examined were serotyped by the indirect haemagglutination test (Shreeve, Biberstein and Thompson, 1972). Biotyping (Smith, 1961) was unnecessary because it is known that biotype A comprises serotypes $1,2,5,6,7,8,9,11,12,13$ and 14 and biotype $T$ comprises serotypes 3,4 and 10 .

\section{RESULTS}

The clinical findings were as described by Stamp et al. (1955).

\section{Pathological findings}

Several previously unreported pathological changes were observed. These consisted of striking lesions in the region of the throat, and histological changes in the brain. In other respects the post-mortem appearance and 
histopathology were as described by Stamp et al. (1955). The frequency with which various macroscopic lesions were seen in the 17 lambs is shown in table I.

Throat and upper alimentary tract. Necrotic erosions of the superficial mucosa (figure) took the form of shallow craters with hyperaemic borders, containing purulent debris and sometimes food particles. Some lesions were discrete, while others, particularly in the upper third and occasionally throughout the whole length of the oesophagus, were confluent, with extensive destruction of the surface. The necrotic lesions affected, and appeared to have spread from, the tonsillar crypts and surrounding epithelium; the epiglottis and oesophagus were affected frequently, and the tongue, buccal cavity, soft palate and nasal septum occasionally. The tonsils and the retropharyngeal and mandibular lymph nodes were consistently enlarged, congested and oedematous. The cervical lymph nodes were often affected also, and sometimes the prescapular nodes; lymph nodes elsewhere in the body showed no macroscopic abnormality.

In the oesophagus the usual histological change was complete necrosis of the squamous lining epithelium, with engorgement of mucosal vessels but little or no cellular reaction. Masses of gram-negative bacteria and gram-positive cocci adhered to the luminal surface, and occluded mucosal venules or lymphatics.

Brain. Two changes predominated. First, serum-protein leakage from vasscular branches occurred in the cerebro-cortical leptomeninges; a similar effect was less consistently seen in the cerebellar meninges. Second, the choroid plexus of the lateral and sometimes the fourth ventricle was usually distended and infiltrated by mononuclear cells. The swelling was due in part to leakage of

TABLE I

Macroscopic lesions in systemic pasteurellosis

\begin{tabular}{l|lc}
\hline \multicolumn{1}{c|}{ Tissue } & \multicolumn{1}{c}{ Lesion or abnormality } & $\begin{array}{c}\text { Number of lambs } \\
\text { (in a series of 17) } \\
\text { with indicated condition }\end{array}$ \\
\hline $\begin{array}{l}\text { Tonsils, pharyngeal } \\
\text { lymph nodes }\end{array}$ & Enlargement & 17 \\
$\begin{array}{l}\text { Larynx, tonsillar } \\
\text { crypts, oesophagus }\end{array}$ & Erosions & 16 \\
Tongue, buccal mucosa & Erosions & 2 \\
Subcutis & Haemorrhages & 13 \\
Lung & Congestion and oedema & 15 \\
& Subpleural haemorrhages & 13 \\
& Air passages filled with frothy fluid & 12 \\
Heart & Consolidation & 4 \\
Liver & Subepicardial haemorrhages & 10 \\
Spleen & Excess pericardial fluid & 1 \\
Rumen & Necrotic foci & 7 \\
Omasum & Congestion & 3 \\
Abomasum & Subcapsular haemorrhages & 3 \\
& Erosions & 1 \\
& Erosions & 2 \\
& Oedema & 5 \\
\hline
\end{tabular}


serum proteins or erythrocytes into the interstitium, but it was due mainly to infiltration of macrophages, plasma cells and lymphocytes. The choroidal vasculature was usually severely congested. In a few instances, the plexus was affected only in discrete foci.

Other findings included small haemorrhages in the cerebral and cerebellar meninges and cortices. Occasionally free macrophages were present in the cerebral meninges, and in four brains focal asymmetric areas of status spongiosus were present in the cerebral and cerebellar peduncles. In one case, bilaterally symmetrical areas of spongy transformation were also present in the tectum of the midbrain. Bacterial emboli were not seen.

\section{Bacteriological findings}

Distribution of $P$. haemolytica in affected lambs. The results of viable counts of $P$. haemolytica in tissues and fluids are given in table II. The tonsils and oesophageal lesions were invariably infected, usually with large numbers of viable organisms. High counts were also frequently obtained from the lung, liver and, to a lesser extent, spleen. In contrast $P$. haemolytica was present only occasionally, and in very low numbers, in the kidney, brain, and abomasal contents. Blood samples from two moribund lambs also yielded very low numbers. The organism was commonly isolated from abomasal lesions. At least half the mediastinal and mesenteric lymph nodes examined were infected, but with two exceptions the counts obtained were very low. Ileal contents were invariably negative.

Biotype and serotype of $P$. haemolytica isolates. Of the 10 lambs subjected

TABLE II

Distribution of Pasteurella haemolytica biotype T in the carcasses of sheep that died from systemic pasteurellosis

\begin{tabular}{l|ccc}
\hline \multicolumn{1}{c|}{ Sample } & $\begin{array}{c}\text { Number of lambs* that } \\
\text { yielded P. haemolytica from } \\
\text { the stated sample }\end{array}$ & $\begin{array}{c}\text { Mean viable count } \\
\text { (log } 10 \text { per g) }\end{array}$ & $\begin{array}{c}\text { Range of } \\
\text { viable counts } \\
\text { (log } 10 \text { per g) }\end{array}$ \\
\hline Lung & $10 / 10$ & $7 \cdot 9$ & $6 \cdot 6-9 \cdot 4$ \\
Tonsil & $10 / 10$ & $7 \cdot 8$ & $6 \cdot 6-8 \cdot 9$ \\
Oesophageal lesions & $8 / 8$ & $7 \cdot 2$ & $5 \cdot 6-8 \cdot 5$ \\
Liver & $10 / 10$ & $7 \cdot 1$ & $5 \cdot 2-8 \cdot 2$ \\
Spleen & $9 / 10$ & $6 \cdot 0$ & $<2 \cdot 0-8 \cdot 0$ \\
Abomasal lesions & $5 / 6$ & $5 \cdot 1$ & $<2 \cdot 0-7 \cdot 8$ \\
Mediastinal LN & $4 / 6$ & $3 \cdot 0$ & $<2 \cdot 0-7 \cdot 9$ \\
Anterior mesenteric LN & $4 / 8$ & $<2 \cdot 5$ & $\ldots$ \\
Posterior mesenteric LN & $7 / 10$ & $<3.0$ & $\ldots$ \\
Kidney & $4 / 10$ & $<3 \cdot 0$ & $\ldots$ \\
Cerebrum & $4 / 10$ & $<2.0$ & $\ldots$ \\
Blood & $2 / 2 \dagger$ & $<2.0$ & $\ldots$ \\
Abomasal contents & $2 / 10$ & $<2.0$ & $\ldots$ \\
lleal contents & $0 / 10$ & 0 & $\ldots$ \\
\hline
\end{tabular}

* Numerator $=$ number of positive lambs; denominator = number of lambs examined. $\dagger$ Lambs alive but moribund.

LN = Lymph node. 


\section{P. HAEMOLYTICA BIOTYPE T IN SHEEP}

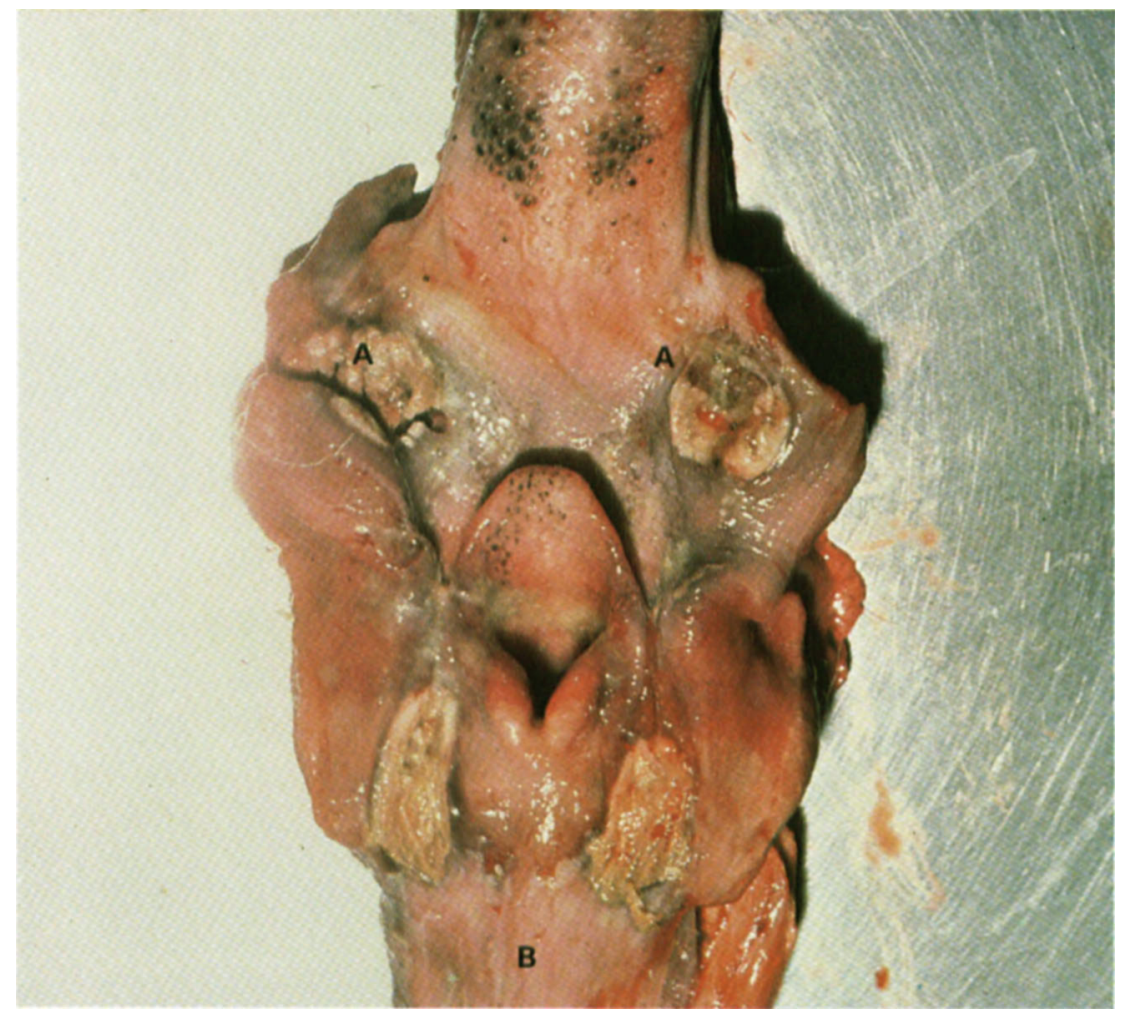

Fig.-Lesions in the throat of a sheep infected systemically with Pasteurella haemolytica biotype T. The pharynx is severely inflamed and there is necrosis of the tonsillar crypts (A) and of the mucosa of the upper oesophagus (B). 
to detailed bacteriological examination, six yielded single types only; the types were T10 (three lambs), T3 (two lambs), and T4 (one lamb). In four lambs that yielded more than one serotype, a single serotype of biotype $T$ predominated; small numbers of a second serotype of biotype $\mathrm{T}$ occurred, mainly in the tonsils. In addition, one of these four lambs yielded type A9 from consolidated lung tissue, and from a mediastinal lymph node; another yielded type A2 from the lung, liver, tonsil and oesophagus, and from a mesenteric lymph node.

\section{Discussion}

Our observations were in general agreement with those of Stamp et al. (1955) and Biberstein and Kennedy (1959), except that we consistently found tonsillar necrosis and enlargement and necrotic erosions of the upper alimentary tract. Necrotic oesophagitis in sheep with systemic pasteurellosis has also been observed by J. Fitton and D. F. Collings (personal communication, 1979). Except in the brain, the occurrence of pathological changes was closely related to the presence of large numbers of $P$. haemolytica in the tissues. Smith $(1960 \mathrm{~b})$ observed that, in three lambs that died from the natural disease, viable counts in the lung, liver and spleen were much greater than those in the kidney. The present study confirms and extends that finding; the mean viable counts in tonsil, lung and liver exceeded by more than $5 \log _{10}$ those found in the kidney, brain and blood. It is likely that the counts recorded in the oesophagus were lower than the true values because sloughing of the mucosa probably removed many organisms.

The cause of death was almost certainly toxaemia from bacterial endotoxins. Smith $(1960 b)$ showed that the lethal intravenous dose of a heat-killed culture of $P$. haemolytica for sheep was only a low multiple of the lethal dose of living culture; before sterilisation it contained $c .10^{10}$ viable organisms. The results reported here show that bacterial numbers of this order are readily achieved in natural infections.

Of the brain changes, serum-protein leakage in the cerebral meninges is the one most likely to reflect a toxaemic state (Buxton and Morgan, 1976; Buxton, Linklater and Dyson, 1978). The presence of brain haemorrhages and congestion must be interpreted with caution because most of the lambs died some hours before necropsy, and many of the more delicate vessels might conceivably have been damaged during removal of the brain. Because the choroid plexus is a favourable site for trapping immune complexes (Lampert and Oldstone, 1974), the cellular activity consistently observed in this site may indicate that the plexus is unduly sensitive to immune complexes or antigens.

Traditional concepts of septicaemia require that bacteria "gain a foothold and multiply in the blood" (Cappell, 1951). Wilson and Miles (1964) define it as "a severe bacteraemic infection ... probably the expression of a rapid and continuous invasion of the blood stream from the (infected) tissues". It is very doubtful that a true septicaemic phase occurs in the so-called septicaemia produced by biotype $T$ in lambs aged 5-12 months. The disease would probably be better described as systemic pasteurellosis. 
We postulate that, in certain undefined conditions, the biotype-T organisms that are known to occur frequently in the tonsils of healthy sheep (Gilmour $e t$ $a l ., 1974)$ multiply and invade the surrounding tissues of the upper alimentary tract, producing necrotic lesions in the pharynx and oesophagus. From these lesions bacteria enter the blood stream, either directly by the venous drainage or indirectly by the lymphatics and jugular vein. Organisms lodging in the lung capillaries produce embolic lesions in which further multiplication occurs. There is then haematogenous spread to the liver, spleen, and perhaps the kidney. This systemic infection is characterised by multiplication in the organs with occasional release of bacteria into the blood stream, and is not primarily an infection of the blood. It is conceivable that organisms swallowed and passed down the alimentary tract become established in the small intestine, enter the hepatic portal system, and spread to the lungs via the hepatic vein, vena cava and heart. Lesions were seen in the omasum and abomasum in some cases, and Stamp et al. (1955) described occasional lesions in the duodenum. However, the small numbers and infrequent presence of organisms in the gut contents and mesenteric lymph nodes suggested that conditions in the lumen of the gut did not favour the survival of $P$. haemolytica. We feel therefore that invasion of the lower alimentary tract is unlikely to be a major factor in pathogenesis.

The question remains as to the factors responsible for initiating the rapid multiplication of pre-existing $P$. haemolytica in the tonsils. Outbreaks of the disease often coincide with a change from poor grazing to a comparatively rich diet (Stamp et al., 1955); there is also circumstantial evidence that adverse climatic conditions and intercurrent disease may play a part (Dyson, unpublished observation).

The proposed pathogenesis of sytemic pasteurellosis needs to be tested by experimental reproduction of the disease and examination of animals killed at intervals after infection. Although a disease resembling systemic pasteurellosis in many though not all respects has been produced by the intravenous injection of large numbers of P. haemolytica (Stamp et al., 1955; Biberstein and Kennedy, 1959; Smith, 1960b; Gilmour, unpublished observation), a more valid approach might be to try to establish infection in the throat and upper alimentary tract, the sites in which the initial multiplication of the organisms is presumed to occur.

We thank Miss J. Walker and Miss K. Donald for capable technical assistance, Mr W. Donachie for the serotyping, and The Wellcome Foundation Ltd and Robert Young and Co. Ltd for help in meeting the cost of the coloured plate.

\section{REFERENCES}

Biberstein, E. L. AND KenNedy, P. C. 1959. Septicemic pasteurellosis in lambs. Am. J. vet. Res., $20,94$.

Buxton, D. AND Morgan, K. T. 1976. Studies of lesions produced in the brains of colostrum deprived lambs by Clostridium welchii (C.perfringens) type D toxin. J.comp. Path., 86, 435.

Buxton, D., Linklater, K. A. AND Dyson, D. A. 1978. Pulpy kidney disease and its diagnosis by histological examination. Vet. Rec., 102, 241. 
CAPPELl, D. F. 1951. Muir's Textbook of pathology, 6th ed., Edward Arnold, London, p. 177.

COOP, R. L., ANgus, K. W. And SykeS, A. R. 1979. Chronic infection with Trichostrongylus vitrinus in sheep. Pathological changes in the small intestine. Res. vet. Sci., 26, 363.

GiLmour, N. J. L. 1978. Pasteurellosis in sheep. Vet. Rec., 102, 100.

Gilmour, N. J. L., Thompson, D. A. AND Fraser, J. 1974. The recovery of Pasteurella haemolytica from the tonsils of adult sheep. Res. vet Sci., 17, 413.

LAMPERT, P. W. AND Oldstone, M. B. A. 1974. Pathology of the choroid plexus in spontaneous immune complex disease and chronic viral infections. Virchows Arch.path. Anat. Physiol., A363, 21.

Miles, A. A., MisRA, S. S. AND IRwin, J. O. 1938. The estimation of the bactericidal power of the blood. J. Hyg., Camb., 38, 732.

ShreEve, B. J., Biberstein, E. L. AND Thompson, D. A. 1972. Variation in carrier rates of Pasteurella haemolytica in sheep. II. Diseased flocks. J. comp. Path., 82, 111.

SMITH, G. R. 1960a. The pathogenicity of Pasteurella haemolytica for young lambs. J. comp. Path., 70, 326.

SmITH, G. R. 1960b. Virulence and toxicity of Pasteurella haemolytica in the experimental production of ovine septicaemia. J. comp. Path., 70, 429.

SмITH, G. R. 1961. The characteristics of two types of Pasteurella haemolytica associated with different pathological conditions in sheep. J. Path. Bact., 81, 431.

Stamp, J. T., Watt, J. A. A. And Thomlinson, J. R. 1955. Pasteurella haemolytica septicaemia of lambs. J. comp. Path., 65, 183.

Wilson, G. S. AND Miles, A. A. 1964. Topley and Wilson's Principles of bacteriology and immunity, 5th ed., Edward Arnold, London, p. 1788. 